\title{
Princípios gerais do emprego de psicofármacos
}

\author{
Heloisa Helena A Brasil
}

Serviço de Saúde Mental da Infância e Adolescência do Instituto de Psiquiatria (IPUB) da Universidade Federal do Rio de Janeiro (UFRJ)

\section{Introdução}

A indicação de psicofármacos para o tratamento de problemas de saúde mental em crianças e adolescentes traz preocupação mas também esperanças. Preocupação pelo risco dessas indicações tenderem a banalizar o uso como solução imediata e não como um recurso possível a partir da avaliação risco-benefício. Esperança pela possibilidade de novas drogas ajudarem a diminuir graves prejuízos que os transtornos mentais acarretam às crianças e aos adolescentes a curto e a longo prazo. Porém, qualquer proposta terapêutica é antecedida por um processo diagnóstico e, mais que no adulto, na criança esse processo diagnóstico é determinante para garantir uma boa orientação terapêutica. No presente artigo serão apresentadas questões referentes ao processo diagnóstico em psiquiatria da infância e da adolescência e os princípios gerais do emprego de psicofármacos nessa faixa etária.

\section{Processo diagnóstico}

Denominar de "processo diagnóstico" as entrevistas com pais e com a criança/adolescente no campo da saúde mental tem sua razão de ser. A investigação clínica da criança tem suas particularidades. Nela, o psiquiatra precisa levar em conta variáveis na maioria das vezes determinantes para se chegar a uma formulação diagnóstica.

Frente às queixas dos pais, é necessário discernir o que eles apresentam como motivo da consulta e o que realmente ocorre com a criança. É preciso ir muito além da queixa dos pais e da história da criança contada por eles. Nem sempre o motivo da consulta e os dados de anamnese são coerentes entre si e com os obtidos no encontro com a criança ou adolescente. O relato dos pais e da criança podem revelar questões parentais ou do grupo familiar, subjacentes, e cabe ao psiquiatra desvendá-las ao longo do processo diagnóstico. O motivo da consulta pode ser constituído de queixas secundárias e encontrar-se deslocado do problema principal. Nesse caso, ao problema principal dá-se o nome de queixa latente, e é tarefa do psiquiatra identificá-la e torná-la consciente aos pais. A queixa latente pode estar relacionada com a própria criança, com um dos pais, com o casal ou com todo o grupo familiar. ${ }^{1}$ A identificação da queixa latente pode mudar o eixo de quem é o paciente. Uma avaliação bem conduzida pode ser terapêutica em si mesma, mais precisamente nesses casos em que possibilita aos pais reformularem o sentido do(s) sintoma(s) do filho ou dos que lhe atribuem indevidamente.

A partir da identificação do problema principal, quando esse envolve o menor, cabe ao psiquiatra obter os dados de anamnese da criança levando em conta o contexto familiar e social; realizar seu exame psíquico; e detectar áreas saudáveis de seu funcionamento, bem como o grau de seu sofrimento psíquico ou o prejuízo nas áreas comprometidas. Também é preciso levar em conta sua idade e seu desenvolvimento motor, cognitivo e emocional.

Uma avaliação adequada oferece condições para o diagnóstico inicial e para o encaminhamento do caso. Este nem sempre inclui a criança ou o adolescente diretamente, podendo restringir-se à orientação, ao acompanhamento ou ao tratamento dos pais. Quando o atendimento envolve a criança/adolescente, este pode ocorrer de modo individualizado (abordagens psicoterápicas individual ou em grupo, uso de psicofármacos, recursos psicopedagógicos) ou associado à assistência a outros membros da família (acompanhamento dos pais, terapia do grupo familiar), e à assistência à escola, entre outros.

\section{Princípios gerais}

Em psiquiatria, os sintomas são considerados inespecíficos. No entanto, o reconhecimento da sua natureza é fundamental para o planejamento global do tratamento, inclusive na escolha da medicação a ser usada. Embora, em grande parte, o emprego de psicofármacos em crianças e adolescentes vise mais os sintomas do que o quadro geral de um transtorno, a escolha da droga deve ser feita a partir de critérios sindrômicos. ${ }^{2} \mathrm{O}$ sintoma, ao pertencer a quadros sindrômicos ou categoriais distintos, receberá indicações de tratamento e/ou de psicofármacos de grupos totalmente diferentes. Por exemplo, num paciente o sintoma de "hiperatividade psicomotora" pode estar presente no transtorno de déficit de atenção/hiperatividade (TDAH), num transtorno difuso do desenvolvimento, no retardo mental, em transtornos do humor, em transtornos de ansiedade e em situações reativas ao ambiente.

Em crianças e adolescentes, alguns transtornos mentais, com freqüência, apresentam comorbidade. A presença de comorbidade influencia o plano terapêutico, a evolução e o prognóstico do quadro clínico. Por exemplo, o TDAH tem melhor prognóstico quando não associado a transtorno de conduta e seu tratamento como quadro único tem muito mais chance de sucesso. Quando em comorbidade a um transtorno depressivo, o planejamento terapêutico precisa levar em conta essa associação.

O tratamento dos transtornos mentais e do comportamento com drogas psicoativas é sintomático e seu uso deve limitar-se ao imprescindível. Na decisão de se usar um psicofármaco, é preciso ponderar se a relação risco-benefício potencial da droga justifica seu emprego e se outros recursos foram devidamente explorados. Para Trallero, ${ }^{2}$ constitui um grave erro de desinformação pensar que os psicofármacos devam ser o último recurso tera- 
pêutico, só usados quando esgotados os demais. Os psicofármacos não são panacéias, mas um recurso de primeira ordem em muitos casos, complementares em outros e, sem dúvida, totalmente inúteis em outros. É preciso conhecê-los, assim como aos demais procedimentos terapêuticos que têm demonstrado ou vêm demonstrando sua eficácia relativa e seus riscos e efeitos secundários - porque todos os têm. ${ }^{3}$ Para Trallero, ${ }^{2}$ a multicausalidade dos transtornos, a complexidade dos sintomas e a influência das interações psicossociais exigem que "na imensa maioria de autênticos transtornos mentais na infância e adolescência os tratamentos devem ser mistos, envolvendo intervenções farmacológicas, psicoterápicas e psicossociais" (p.18). Portanto, o uso da medicação não deve constituir "o tratamento da criança" mas sim fazer parte de um plano mais amplo em que outros tipos de intervenções também sejam incluídas.

No tratamento psicofarmacológico, é importante não buscar objetivos gerais, mas específicos, de acordo com o sintoma-alvo. Isso possibilita melhor controle da eficácia da medicação, controle do tempo de tratamento e a individualização do mesmo para cada criança. Além disso, permite explicar à família o que esperar do tratamento farmacológico. Ou seja, esclarecer que a medicação é sintomática, que nem sempre vai resolver o problema de base (p. ex. na psicose infantil e no autismo), mas que seu uso pode melhorar a qualidade de vida da criança e dos familiares. Também é importante explicar aos pais ou responsáveis que cada medicação requer um determinado período de tempo para agir (podendo levar mais de uma semana para começar a fazer efeito) e que não se deve interromper abruptamente o uso de determinadas drogas. Informações simples podem favorecer a adesão da família e da criança ao tratamento, tornando-os melhores informantes da atuação e dos efeitos do medicamento. Por sua vez, o clínico tem que julgar se a família (e especialmente o adolescente) é suficientemente esclarecida e responsável para o cumprimento de determinadas normas e cuidados necessários, por exemplo no controle clínico do lítio. Como procedimento inicial, queixas somáticas, esteriotipias, maneirismos e tiques devem ser registrados para não serem confundidos, posteriormente, com efeitos colaterais ou adversos.

O uso concomitante de vários psicotrópicos, seja para potencializar efeitos, pela presença de comorbidades ou de outras condições médicas associadas, tem sido freqüente. ${ }^{4} \mathrm{O}$ maior conhecimento do metabolismo dos psicotrópicos tem fornecido dados mais consistentes sobre interações medicamentosas, principalmente das drogas metabolizadas por isoenzimas do citocromo P450 (CYPs). Com base nesses conhecimentos recentes, o uso concomitante de medicamentos tem gerado preocupação tanto pela possibilidade de diminuírem a ação das drogas envolvidas, quanto pelo potencial de causarem toxicidade.

Em crianças e adolescentes, a associação de psicofármacos entre si ou com medicamentos para problemas clínicos (p. ex. acne, candidíase, problemas de vias aéreas superiores, entre outros) requer cautela. Benzodiazepínicos (alprazolam ou clonazepan), quando associados à eritromicina oral (usada em infecções cutâneas) ou ao cetoconazol oral (medicação usada na candidíase ou outras infecções micóticas), têm seus metabolismos alterados, pois a eritromicina e o cetoconazol são dois potentes inibidores do CYP3A. O lorazepam não é metabolizado via CYP e deve ser a opção de escolha nessas situações. A claritromicina, antibiótico usado no tratamento de infecções de vias aéreas superiores e de outros tipos de infecções, é um potente inibidor do CYP3A e, se usado com determinados neurolépticos (risperidona, pimozide, haloperidol), pode levá-los a níveis tóxicos. ${ }^{4}$

Por sua vez, durante a pré-puberdade, a atividade dos CYPs atinge sua maior eficiência, para diminuir após a puberdade para níveis encontrados nos adultos. Isso talvez explique a necessidade de doses proporcionalmente mais altas (relação dose/ $\mathrm{kg}$ ) para drogas metabolizadas pelos CYPs (p. ex., antidepressivos tricíclicos, valproato de sódio, carbamazepina, pimozide) nos pré-púberes em relação aos adultos. ${ }^{4}$

Os seguintes endereços na Internet oferecem dados sempre atualizados sobre CYPs: ${ }^{4}$

- http://www.dml.georgetown.edu/depts/pharmacology/ clinlist.html

- http://www.accp.com/p450.html

- http://www.mhc.com/cytochromes

Em resumo, a escolha da medicação é influenciada por sintomas, isolados ou não, pelo diagnóstico principal, pela(s) comorbidade(s), pela idade, pelas condições clínicas do paciente e pelo uso concomitante de outros medicamentos.

\section{Conclusão}

Atualmente, as poucas informações disponíveis sobre eficácia e segurança dos psicofármacos em pediatria deixa o psiquiatra na incerteza de quando e como usá-los. Um amplo e atualizado conhecimento em psicopatologia e psicofarmacologia e o emprego consciencioso de psicofármacos, associado a outras modalidades de tratamento, podem auxiliar crianças e adolescentes a alcançar uma qualidade de vida melhor.

\section{Referências}

1. Brasil HH. O exame psiquiátrico da criança. In: Porto CC, ed. Semiologia médica. 3" ed. Rio de Janeiro: Guanabara Koogan; 1997. p. $1085-95$.

2. Trallero JT. Introducción a la psicofarmacología clínica de la infancia y la adolescencia. In: Trallero JT, Fornieles JC, Giral MG, Garcia LL. Psicofarmacología clínica de la infância y la adolescencia. Barcelona: Masson; 1998. p.1-37.
3. Trallero JT. A modo de prólogo. In: Trallero JT, Fornieles JC, Giral MG, Garcia LL. Psicofarmacología clínica de la infância y la adolescencia. Barcelona: Masson; 1998. p. VII-IX.

4. Flockhart A, Oesterheld JR. Cytochrome P450 - mediated drugs interations. Child Adolesc Psychiatr Clin N Am 2000;9(1): 43-76.

Correspondência: Heloisa Helena Alves Brasil

Rua Gomes Carneiro, 64/301 Ipanema - 22071-110 Rio de Janeiro, RJ, Brasil - E-mail: helbra@ prolink.com.br 